\title{
Greeks Primary Students' Attitudes Concerning the Inclusion of Special Educational Needs Students in the Mainstream School
}

\author{
Tsakiridou, Helen \\ Professor of Applied Statistics \& Educational Research, \\ Vice Rector of Academic and Administrative Affairs, \\ University of Western Macedonia, Greece \\ Polyzopoulou, Konstantia \\ Department of Primary Education \\ University of Western Macedonia \\ Florina, Greece
}

\begin{abstract}
The current study was conducted in order to examine primary general education children attitudes toward the inclusion of their peers with special educational needs and to identify the factors that affect their attitudes. The sample consisted of 1066 primary mainstream students, who completed the "Attitudes toward inclusion scale" (Gash, 1993; Gash \& Coffey, 1995; Gash, 1996). The results showed that children are adopting the act of being sociable to special needs students and liking to meet and spend time with them. Concerning the total integration in the general education, a great part of students, are disposed in a positive but typical way to be co-educated in the same school environment with their peers with disabilities. The research, pointed out the need to focus on the study of social interactions between typically developing students' attitudes and their special needs peers.
\end{abstract}

Keywords:attitudes, inclusion, special needs, primary students, sociability, schooling.

\section{Introduction}

Integration of diversity is the basic purpose in a complex and dynamic school system, for the inclusion provision to be achieved (Katsama \& Bourmpaki, 2017). The procedure of inclusion is the responsibility of all members of school system (Kazimi \& Kazmi, 2018) and it is for that reason that changes should be applied in the educational system (Oswalt \& Swart, 2011).According to the inclusive education philosophical frame, schools are formed in order for the needs of all students to be satisfied. In case a student encounters difficulties that function as a barrier during the learning process, it is then that the problem should be identified in the context of learning strategies that are used and the school function, and not to be searched in the student (Sharma, Loreman \& Forlin, 2012).

\section{General primary education children attitudes toward the students with special educational needs.}

Personal attitudes are described as beliefs and opinions that express a person related to a subject, as disability or multiculturalism. Social attitudes are referred to prevailing beliefs adopted and influenced by governing systems, cultural orientation, historical background, or other applicable conditions. Social attitudes are characterized by the tendency to be removed more easily and they are not necessarily in accordance with personal attitudes (Daruwalla \& Darcy, 2005).According to a study (Magiati, 2002), a great part of the sample expressed positive attitudes toward the students with disabilities, they appeared willing to co-exist with their special needs peers in the same classroom and they used confusing terms to describe the concept of disability. In a similar study (Eleftheriou et al., 2013), students appeared to lack of knowledge about the difficulties that disabled persons are facing.

In another research (Skär, 2010), students attributed to the concept of disability medical causes, mention that a technical support should be provided to the disabled person, with special help, and they appeared to be acceptable of the policy for that student with disability to be integrated in the peers group. Furthemore, it was found that (King et al., 1989), favorable attitudes to the disabled can derive from children who are socially valued by others, a fact that can reinforce their sense of security and confidence during their social interactions.

\section{Method}

\subsection{Sample}


In our study participated 1020 typically developing primary education students, 484 of those were boys and 536 were girls. Among the total number of students, 266 were staying in a big city and 793 were staying in urban areas. The students' age range from 7 to 13 years old. More specifically, 384 students were aged from 7 to 9 years old, 427 students were aged from 11 to 13 years old and 214 students were 10 years old. Furthermore, 113 participants attended the first (A) and second (B) grade, 214 participants attended the third (C) grade, 202 participants attended the fourth (D) grade, 246 students attended the fifth (E) grade and 271 students attended the sixth (ST) grade of general primary school. The students of the sample were born during the years 2004 to 2009 . Particularly, 207 students were born during the years 2004 to 2005, 263 students were born the year of 2006, 136 pupils were born the year of 2007, 198 pupils were born the year of 2008 and 147 students were born the year of 2009 (Table 1).

Table 1.Demographic characteristics of the participants

\begin{tabular}{|l|l|l|l|}
\hline Demographic variables & Participants & Total (f) & $\begin{array}{l}\text { Relative Frequencies } \\
(\%)\end{array}$ \\
\hline \multicolumn{4}{|c|}{$\mathrm{N}=1066$} \\
\hline Gender & Boy & 484 & 45.4 \\
\hline & Girl & 536 & 50.3 \\
\hline Place of residence & Big city & 266 & 25.0 \\
\hline & Urban area & 793 & 74.4 \\
\hline Age & $7-9$ years & 384 & 36.0 \\
\hline & 10 years & 214 & 20.1 \\
\hline & $11-13$ years & 427 & 40.1 \\
\hline Grade - class & A - B & 113 & 10.6 \\
\hline & C & 214 & 20.1 \\
\hline & D & 202 & 18.9 \\
\hline & E & 246 & 23.1 \\
\hline & ST & 271 & 25.4 \\
\hline Year of birth & $2004-2005$ & 207 & 19.4 \\
\hline & 2006 & 263 & 24.7 \\
\hline & 2007 & 139 & 13.0 \\
\hline & 2008 & 198 & 18.6 \\
\hline & 2009 & 147 & 13.8 \\
\hline
\end{tabular}

Missing data: 46 for gender (4,3\%), 7 for place of residence (0,7\%), 41 for age (3,8\%), 20 for class (1,9\%), 112 year of birth $(10,5 \%)$.

\subsection{Instrument}

Two parts of the "Attitudes toward inclusion scale" (Gash, 1993; Gash \& Coffey, 1995; Gash, 1996) was used in our study. This scale constitutes a psychometric tool designed to measure typical students' attitudes toward students with special needs. The original scale includes three sections: The first part is referred to an attitude scale, where 20 questions are related to a special needs child and starts with the following instructions: I would like you to think that a young boy or a young girl came to your class this year and has a special need (does not see well, or hears badly, or has problems walking, or learns slowly). Here are some questions for you to answer". In this scale, the items are graded as following: 1 for "yes", 2 for "sometimes" and 3 for "no". The second part is consisted of a 34-adjective list, where the children are asked to describe a special needs child using words among a list of proposed adjectives, after the following question: If you were describing him / her to your other friends, which of these words do you think you would use? The third part was consisted of questions to assess child's experience with children with special needs: Are there any children with special needs in your school / class? Do you know anybody who has special need? (Gash, 1996).

For the original scale, an orthogonal factor analysis was conducted according to Gash method (1993), where four factors were emerged, with eigenvalues larger than one, that accounted the $47 \%$ of the distribution. The results showed two factors, loading higher than 0.40, concerning the "sociability" factor (items 2-6 and 11; items 1, 7-10, 12 and 14) and two factors were related to "education" (items 18-20; items 13, 25, 16). Three of these factors were similar to those emerged in the initial study, but not the fourth one, where Cronbach's' a was not acceptable $(a=0.39)$. The factors were related to "sociability" and "education" and they were tested for their internal consistency, using the Cronbach's a procedure (Items 1-14 and 17; and items 15, 16 and 18-20). There were four items extracted from the factor "sociability", because this way, Cronbach's a value was increased. 
Factor analysis results supported this approach, while the three factors analysis has led to the following problems (Cronbach's a $=0.40)$ : a) items related to maths and reading ability (15 and 16) loaded on both factors, "sociability" and "education", b) the third factor was not easily interpretable. Consequently, the two factor analysis was chosen to create variables for analysis, according to the Cronbach's a result analysis described above. The factor "sociability" consists of items 2-12, and the Cronbach's a resulted equal to 0.74 ; the factor "education" consists of items 15,16 and 18-20, and the Cronbach' s a resulted equal to 0.65 . The scores of these items, constructing each of the two factors, were added separately for each factor, in order to form two factors, appropriate to be used as dependent variables for data analysis. Each item was coded as following: "yes" was scored 1, "sometimes" was scored 2, and "no" was scored 3. Three items (item 9, about tolerance for not knowing game rules; item 19, about the need for a special needs student to be educated in a special classroom; item 20, about the need of a special needs student to be educated in a special education school), were scored reversely $(1=3,3=1)$ in order to contribute in a positive way to those factors. Low score in factor "sociability", indicates higher grade of "sociability", via greater number of "yes" and "sometimes" responses. Low scores in items that form "education" factor, show that children develop positive attitudes toward the perspective of inclusion. High scores in the factor of "education" reflect the belief that special needs children are not able to correspond to the learning requirements of mathematics and language subjects in a typical classroom and they have to attend a special education school or a special education classroom.

The questionnaire used in the current research includes two parts: The first area is constituted by 20 items, each of them is scored in a three point Likert scale, where responses for "yes" were scored 1, responses for "sometimes" were scored 2 and responses for "no" were scored 3. The second part is referred to demographic characteristics (age, class, gender) and the following questions: Have you ever read about disability in a book, journal or newspaper? Have you ever watched a television document about children with special needs? Have you ever been informed about disability by a family member or an adult? (Siperstein et al., 2011). Do you have a friend with disabilities or with special needs? Are there in your school children with special needs or disabilities? (Gash \&Feerick, 1996).

In the original questionnaire was used the term "mental retardation", as it was used in the survey of Gash and Coffey (1995). In the later years, the term "mental retardation" was replaced by the phrase "special needs" and "Down syndrome" (Gash et al., 2000; Gannon \& McGilloway, 2009).

The current scale has been used in previous studies in the area of Greece. These studies were related to primary education students' representations about disability (Magiati et al., 2002) and to children's attitudes about special needs students (Soulis et al., 2016). There were also studied children's attitudes toward students with physical disabilities (Nikolaraizi \& DeReybekiel, 2001; Kalyva \& Agaliotis, 2009) and mental retardation (Georgiadi et al., 2012). Another similar study was conducted in Iran (Shamsi et al., 2014), where primary education girls expressed their attitudes about their peers with disabilities and in China (Tang et al., 2000), where students aged 4 to 15 years old had to express their perceptions about students with mental retardation and the required school arrangements for the students with special needs, in order for them to be included in mainstream schools. The same scale was used in studies that took place in other European Countries (Gash et al., 2000), including the Country of Ireland (Gannon \& McGilloway, 2009) where primary students' attitudes toward their peers with Down syndrome were assessed.

For the current version of the questionnaire, items were translated in order to evaluate Greek Primary students' attitudes toward their special needs peers. For that reason, two bilingual translators were participated in the translation process independently. After the process was completed, the scale was distributed to a small sample of the study population (De Boer, 2012) (5 primary education students who attend general education schools), who completed the questionnaire and wrote down their remarks concerning the wording and the content of the items, to identify ambiguities and make expression improvements. Then, the translated scale was given to two educators, to check the formulation of the items, to understand their meaning and to check other issues. The procedure of "back translation" was followed and the initial questionnaire was translated in the English language by two researchers, specified in the construction of attitudes psychometrics instruments, in order for the internal consistency of the scale to be verified, according to the content structure analysis (Weber, 1990).

\subsection{Procedure}

In the current research, participated primary education students of general education schools, located in big city and urban areas. For the survey to be conducted, it was used the stratified sampling based on the population of departments in Greece. Schools were listed in a catalogue, where primary education mainstream schools were included, per region, at perfection level. Data collection was held by the participation of thirteen (13) primary general education schools (nine (9) schools are located in urban areas and four (4) schools are located in a big city). During school year of 20162017, the survey was completed with the participation of nine (9) schools, from April of 2017 to June of 2017 and, during school year of 2017-2018, four (4) schools were participated, from October of 2017 to December of 2017. 
As necessary condition for the students' participation in the study, the researchers followed the research instructions given by the Greek Ministry of Education, Research and Religious Affairs. The official survey permission was given for the school year of 2016-2017 and it was requested a permission approval for the school year of 2017-2018. Subsequently, a contact with the Director of Primary Education office, per regions, was held, in order for the directors to be informed about the survey. Then, the school principals were notified about the survey and its purpose, and after the completion of the parental consent form, the researchers visited each school, where the questionnaires were distributed to the students.

The research conducted in the classroom (Demellweek et al., 1997), with the presence of the principal and the teacher, who has been informed about the survey by the principal in a previous time. Before the completion of the scale, there were given to the students the following instructions: I would like you to think that a young boy or a young girl came to your class this year and has a special need (does not see well, or hears badly, or has problems walking, or learns slowly). Here are some questions for you to answer, concerning that child". The students were also informed that at the second page of the questionnaire, there were demographics data to be completed as well. They were also informed, that we received their parent' s consent, in order to participated in the study. It was pointed out that there are no right nor wrong answers (it is not a test), their participation is voluntary, the data will be used for educational and research purposes and the answers will be remain anonymous.

\subsection{Data analysis}

Statistical analysis included the use of Statistical Package of Social Analysis (SPSS 20). Especially, it was used Factor analysis, Cronbach' s a reliability analysis, Pearson correlation analysis, Independent Samples T-test and Univariate ANOVA, to locate possible differences among variables.

\section{Results}

4.1 Factor Analysis of the questionnaire of the "Attitudes toward inclusion scale" (Gash, 1993; Gash \& Coffey, 1995; Gash, 1996).

The questionnaire contains 20 items. The results confirmed the two factors (KMO $=.844$, Bartlett's Test of Sphericity $=2794.63, \mathrm{df}=190, \mathrm{p}=0.000, \mathrm{p}<0.001)$. The two factors resulted from the present study contain the same number of items as those of the factors in the original questionnaire. Similar results concerning the factor analysis of the scale were noted in previous studies (Gash et al., 2000; Gannon \& McGilloway, 2009), where two factors were emerged: a) sociability and b) schooling (school education - total integration - inclusion in the mainstream school). In the current study, the first factor (F1), contains eleven (11) items, it was called "sociability" (Cronbach's a $=.787$ ) (Table 2) and it explains the $33.4 \%$ of total variance. The second factor (F2) consisted of five (5) items, it was called schooling (school education - total integration - inclusion in the mainstream school) (Cronbach's a $=.742$ ) and it explains the $21.9 \%$ of total variance (Table 2).

Table 2.Cronbach' s a reliability analysis of the "Attitudes toward inclusion scale" (Gash, 1993; Gash \& Coffey, 1995; Gash, 1996).

\begin{tabular}{|l|c|}
\hline \multicolumn{1}{|c|}{ Factors } & $\begin{array}{c}\text { Cronbach' s } \\
\mathrm{N}=1020\end{array}$ \\
\hline Sociability & .787 \\
\hline Schooling (total integration - inclusion) & .742 \\
\hline
\end{tabular}

The following table (Table 3) presents the factor analysis (principal components analysis with varimax rotation) carried out for the current version of the questionnaire after its administration to the primary education students of the study. A moderate level correlation between the two factors is showed in Table 4, which expresses a positive direction and indicates a statistical significant difference in the level of $\mathrm{p}<0.01$. The means and standard deviations of the sample are presented in Table 5 . 
Table 3.Factor analysis with varimax rotation for the Greek version of the "Attitudes toward inclusion scale" (Gash, 1993; Gash \& Coffey, 1995; Gash, 1996)

\begin{tabular}{|c|c|c|c|c|}
\hline \multirow{2}{*}{ Items } & \multicolumn{4}{|c|}{ Factors } \\
\hline & F1 & $\mathrm{F} 2$ & Mean & SD \\
\hline Would you invite him / her to your house to play in the evenings? & .703 & & 1.67 & .732 \\
\hline Would you ask him / her to seat beside you? & .701 & & 1.54 & .721 \\
\hline $\begin{array}{l}\text { Would you invite him / her to your birthday party with your other } \\
\text { friends? }\end{array}$ & .626 & & 1.28 & .579 \\
\hline Would you make him / her your best friend? & .615 & & 1.79 & .842 \\
\hline Would you pick him / her on your team in a competition? & .582 & & 1.49 & .697 \\
\hline Would you chat to him / her at the break? & .580 & & 1.38 & .602 \\
\hline $\begin{array}{l}\text { Later on, would you tell him / her secrets that you usually keep for your } \\
\text { friends? }\end{array}$ & .570 & & 2.09 & .823 \\
\hline Would you like to go to his / her party? & .561 & & 1.15 & .463 \\
\hline Would you lend him / her a story - book you liked? & .458 & & 1.45 & .720 \\
\hline Will you help him / her with his / her homework? & .458 & & 1.34 & .599 \\
\hline $\begin{array}{l}\text { Would you feel angry if he / she did not keep the rules of your games at } \\
\text { playtime? }\end{array}$ & .423 & & 1.70 & .811 \\
\hline $\begin{array}{l}\text { Should children with special needs have their own special classroom in } \\
\text { your school? }\end{array}$ & & .637 & 2.23 & .896 \\
\hline $\begin{array}{l}\text { Should children with special needs have their own special school where } \\
\text { all the children have special needs? }\end{array}$ & & .617 & 2.45 & .818 \\
\hline $\begin{array}{l}\text { Do you think the child with the special needs could read the same books } \\
\text { as you? }\end{array}$ & & .574 & 1.76 & .803 \\
\hline $\begin{array}{l}\text { Do you think children with special needs should be taught in the same } \\
\text { classroom as other children? }\end{array}$ & & .555 & 1.66 & .822 \\
\hline $\begin{array}{l}\text { Do you think the child with special needs could do the same maths as } \\
\text { you? }\end{array}$ & & .521 & 1.92 & .826 \\
\hline
\end{tabular}

Table 4.Intercorrelations (Pearson's r) between the two factors of the "Attitudes toward inclusion scale" (Gash, 1993; Gash \& Coffey, 1995; Gash, 1996).

\begin{tabular}{|l|l|l|}
\hline Factors & 1 & 2 \\
\hline Sociability & 1 & $.286^{* *}$ \\
\hline Schooling (total integration - inclusion) & $.286^{* *}$ & 1 \\
\hline
\end{tabular}

Note: $\mathrm{p}<0.01$

Table 5.Means and Standard Deviations of the "Attitudes toward inclusion scale" (Gash, 1993; Gash \& Coffey, 1995; Gash, 1996).

\begin{tabular}{|l|l|l|}
\hline Factors & M & S. D. \\
\hline Sociability & 1.52 & .39 \\
\hline Schooling (total integration - inclusion) & 2.00 & .49 \\
\hline
\end{tabular}

4.2 The relationship between demographic variables and primary education students' attitudes toward children with special educational needs.

Concerning the gender, a statistically significant difference was observed for the first factor. Boys' attitudes $(\mathrm{M} .=1.57$, S. D. $=0.40)$ are different from girls' attitudes $(M=1.47$, S. D. $=0.35)$ for the factor "sociability" $(\mathrm{t}=3.723, \mathrm{df}=887$, $\mathrm{p}=.000, \mathrm{p}<0.001)($ Table 6$)$.

Respecting to book, journal or newspaper information about the disability, there were observed statistical significant differences for the two factors. Specifically, students' attitudes who have been informed from a source mentioned above $($ M. $=1.44$, S.D. $=0.35)$ are different for the factor "sociability" from students' attitudes who haven' $t$ been informed $(\mathrm{M} .=1.58$, S.D. $=0.40)$ from any relevant document $(\mathrm{t}=5.561, \mathrm{df}=906, \mathrm{p}=.000, \mathrm{p}<0.001)$. Moreover, students who have received information about special needs $(\mathrm{M} .=1.95, \mathrm{~S} . \mathrm{D} .=0.50)$ are expressing different attitudes for the factor "schooling" compared to those who have received no information $(\mathrm{M} .=2.05, \mathrm{~S} . \mathrm{D} .=0.48)(\mathrm{t}=3.013, \mathrm{df}$ $=960, \mathrm{p}=.003, \mathrm{p}<0.01)$ (Table 6). Differences were also remarked in the variable television information about disability. 
Students who have watched a television program or an advertise concerning special needs $(\mathrm{M} .=1.46, \mathrm{~S} . \mathrm{D} .=0.34)$ adopt different attitudes from those who have not watched any program (M. = 1.61, S. D. $=0.43$ ) for "sociability factor" $(\mathrm{t}=5.486, \mathrm{df}=596.838, \mathrm{p}=.000, \mathrm{p}<0.001)$ (Table 6). Statistical significant differences were observed for "schooling" factor, between those students who have been informed about disability from television (M. $=1.97, \mathrm{~S}$. D. $=0.49)$ and those who haven't been informed by any relevant television program $(\mathrm{t}=3.443$, $\mathrm{df}=964, \mathrm{p}=.001, \mathrm{p}<0.01)$ (Table 6).Adult information about disability differentiated students" attitudes about their special needs for factor "sociability". Children who have been informed by an adult person about disability $(\mathrm{M} .=1.49, \mathrm{~S} . \mathrm{D} .=0.36)$ seem to express different attitudes from those who have received no information $(\mathrm{M} .=1.58, \mathrm{~S}$. D. $=0.42)$ for factor "sociability" $(\mathrm{t}=$ $3.224, \mathrm{df}=899, \mathrm{p}=.001, \mathrm{p}<0.01$ ) (Table 6).A student with disability or special educational needs in the school has an effect on children' attitudes for the second factor. The attitudes of students who had a peer with special needs in school $(\mathrm{M} .=2.08, \mathrm{~S} . \mathrm{D} .=0.47)$ are statistically different from those student's attitudes who had not any peer with special needs in school $(\mathrm{M} .=1.92, \mathrm{~S} . \mathrm{D} .=0.51)$ for "schooling" factor $(\mathrm{t}=4.807, \mathrm{df}=961, \mathrm{p}=.000, \mathrm{p}<0.001)($ Table 6$)$. Statistical significant differences were noted in the variable special needs student in class for the second factor. Students who had a classmate with disability in their classroom (M. 2.12, S. D. $=0.50$ ) develop different attitudes from those student' $\mathrm{s}$ attitudes who have no special needs peer in their class $(\mathrm{M} .=1.99, \mathrm{~S} . \mathrm{D} .=0.49)$ for "schooling" factor $(\mathrm{t}=2.697, \mathrm{df}=965, \mathrm{p}=.007, \mathrm{p}<0.01)$ (Table 6).Differences were also remarked in the age of the students who participated in the study for factor "sociability" (F 2, $889=6.379, \mathrm{p}=.002, \mathrm{p}<0.01)$. Post hoc analysis using the LSD test indicated these differences between the age group of 7-9 years $(\mathrm{M} .=1.46, \mathrm{~S} . \mathrm{D} .=0.40)$ and $11-13$ years $(\mathrm{M} .=1.56$, S.D. $=0.35$ ) for "sociability" factor (Table 7).

Considering the class, statistical significant differences were emerged for the first factor $(\mathrm{F} 4,905=9.240, \mathrm{p}=.000, \mathrm{p}$ $<0.001)$. According to LSD test, differences were observed between A - B class of primary education $(\mathrm{M} .=1.34, \mathrm{~S}$. D. $=0.40)$ and D' class $(M .=1.57$, S. D. $=0.42), \mathrm{A}-\mathrm{B}$ class $(\mathrm{M} .=1.34, \mathrm{~S} . \mathrm{D} .=0.40)$ and C class $(\mathrm{M} .=1.53, \mathrm{~S} . \mathrm{D} .=$ $0.37), \mathrm{A}-\mathrm{B}$ class $(\mathrm{M} .=1.34, \mathrm{~S} . \mathrm{D} .=0.40)$ and ST class $(\mathrm{M} .=1.58, \mathrm{~S} . \mathrm{D} .=0.34)$. Additionally, for the same factor, differences were observed between $\mathrm{C}$ class $(\mathrm{M} .=1.43, \mathrm{~S} . \mathrm{D} .=0.35)$ and $\mathrm{D}$ class $(\mathrm{M} .=1.57, \mathrm{~S} . \mathrm{D} .=0.42), \mathrm{C}$ class $(\mathrm{M}$. $=1.43, \mathrm{~S} . \mathrm{D} .=0.35)$ and $\mathrm{E}$ class $(\mathrm{M} .=1.53, \mathrm{~S} . \mathrm{D} .=0.37), \mathrm{C}$ class $(\mathrm{M} .=1.43, \mathrm{~S} . \mathrm{D} .=0.35)$ and ST class $(\mathrm{M} .=1.58$, S.D. $=0.34)($ Table 7).

Table 6.Means and Standard Deviations for statistical significant differences of the variables for the factors of the "Attitudes toward inclusion scale" (Gash, 1993; Gash \& Coffey, 1995; Gash, 1996), based on T-test

\begin{tabular}{|l|l|l|l|l|l|}
\hline Factors & Students group & & N & M & S. D. \\
\hline Sociability & Gender & Boys & 417 & 1.57 & $0.40^{* * *}$ \\
\hline & & Girls & 472 & 1.47 & $0.35^{* * *}$ \\
\hline & Book, journal, newspaper information & No & 475 & 1.58 & $0.40^{* * *}$ \\
\hline & & Yes & 433 & 1.44 & $0.35^{* * *}$ \\
\hline & Television information & No & 344 & 1.61 & $0.43^{* * *}$ \\
\hline & & Yes & 569 & 1.46 & $0.34^{* * *}$ \\
\hline & Adult information & No & 284 & 1.58 & $0.42^{* *}$ \\
\hline & & Yes & 617 & 1.49 & $0.36^{* *}$ \\
\hline Schooling (Total integration - inclusion) & Book, journal, newspaper information & No & 497 & 2.05 & $0.49^{* *}$ \\
\hline & & Yes & 465 & 1.96 & $0.50^{* *}$ \\
\hline & Television information & No & 377 & 2.07 & $0.49^{* *}$ \\
\hline & & Yes & 589 & 1.96 & $0.49^{* *}$ \\
\hline & Special needs student in school & No & 452 & 1.92 & $0.51^{* * *}$ \\
\hline & & Yes & 511 & 2.08 & $0.47 * * *$ \\
\hline & Special needs student in classroom & No & 853 & 1.99 & $0.49^{* *}$ \\
\hline & & Yes & 114 & 2.12 & $0.50^{* *}$ \\
\hline
\end{tabular}

Note: Level of significance: $\mathrm{p}, 0.01^{* *}, \mathrm{p}<0.001^{* * *}$ 
Table 7.Means and Standard Deviations for statistical significant differences of the variables for the factor "sociability" of the "Attitudes toward inclusion scale" (Gash, 1993; Gash \& Coffey, 1995; Gash, 1996), based on LSD test.

\begin{tabular}{|l|l|l|l|l|l|}
\hline Factor & Students group & & N & M & S. D. \\
\hline Sociability & Age & 7-9 years & 320 & 1.46 & $0.40^{* *}$ \\
\hline & & $11-13$ years & 385 & 1.56 & $0.36^{* *}$ \\
\hline & Class & A-B & 89 & 1.34 & $0.40^{* * *}$ \\
\hline & & C & 180 & 1.43 & $0.35^{* * *}$ \\
\hline & & D & 179 & 1.57 & $0.42^{* * *}$ \\
\hline & & E & 222 & 1.53 & $0.37^{* * *}$ \\
\hline & & ST & 240 & 1.58 & $0.34^{* * *}$ \\
\hline
\end{tabular}

Note: Level of significance: $\mathrm{p}, 0.01^{* *}, \mathrm{p}<0.001^{* * *}$

\section{Discussion}

Regarding the issue of gender, the study showed that girls expressed a higher level of social acceptance and that they were more supportive toward the students with disabilities in comparison to the boys' attitudes, a finding that is in agreement with previous studies (Gash, 1993; Gash et al., 2000; De Boer et al., 2012;Nowicki, 2006; Soulis et al., 2016; Townsend, Wilton \& Vakilirad, 1993). According to the research, gender differences concerning students' attitudes toward disability were emerged in a way that reflect the differences in the criteria that are used in order to define the degree of disability (Royal \& Roberts, 1987; Tang et al., 2000). Same findings revealed another study (Nabors \& Larson, 2002; Tavares, 2011), where girls expressed higher levels of play - cooperation with a child with disability, compared to boys. Children may express their positive intentions toward the children with specific types of disabilities, because it is "socially desirable" to act in that way, in order to confirm the attitude about the behavior that has to be expressed by the "good boys" and the "good girls" toward a person with disability (Swaim\& Morgan, 2001). Students who have read a document (book, journal or newspaper) related to disability are seem to be more willing to create social relationships with their special needs peers in comparison to those students who haven' $t$ read any similar document and accept the total integration of their disabled peers. Similar research indicated that reading a book about disability or having a friend with disability (Vignes et al., 2009) can have a positive effect in children's attitudes. Furthermore, television programs about disabilities influence students' attitudes and their social acceptance toward a peer with disability, becoming in favor of the total integration. This knowledge is related to the information about a student with disability, the way the disability itself affects and directs the possibilities of children with disabilities and the way the typically developing students are interacting with their special needs peers (Tavares, 2011). This type of contact with disability influences their attitudes (Royal \& Roberts, 1987) and establishes the appropriate conditions of acceptance in the social and school environment. It is observed that the increasing amount of information given by any source that promotes positive attitudes towards disability and their acceptance, may have had a positive impact on children's attitudes and directed their responses to a more "socially desirable" manner(Morgan et al., 1998; Morgan \& Wisely, 1996).

Students who have received information from an adult about the disabilitytend to be more willing to develop social relationships with their special needs peers. According to studies (Soulis et al., 2016; Vignes et al., 2009) students who gain knowledge about special needs by their parents, dispose positive attitude regarding children with disabilities, because parent, who maintain positive attitudes, affect children's attitudes (Tang et al., 2000) and it is also likely for the teachers to influence children's attitudes towards their peers with disabilities in a great extend (Martinez \& Carspecken, 2007). Nevertheless, parents can play a significant role on children's attitudes enhancing their social-emotional development and their behavior in school (Barch, Karnes, \& Rice, 2018).

A special needs student attendance in general education school affects children's attitudes, in a way that, students who had a peer with disability in school, they tend to accept, in a reserved and conservative way, the inclusive education of special educational needs students in mainstream school, in comparison to students who had no student with disability in their school, who express more positive attitudes toward the policy of total integration in the general school. In particular, the conservative tendency seems to result from the participation and involvement of the students in activities that are organized in the same school environment (Townsend, Wilton, \& Vakilirad, 1993), where there is observed a conventional form of interactions. Students are involving in activities with their peers with disabilities in the same school, in a typical level of sharing (Laws \& Kelly, 2005). 
Typical developing students, who attend a school, where there is no peer with special needs, tend to believe that students with disabilities do not prefer to share only the company of the group of special needs students (Soulis et al., 2016), and it is probably for that reason that the students of the current study, who had no child with disabilities in their school, express a willing and positive attitude toward the schooling of that child in a general education school. It is also noticed that, students who attend a school where there is included an integration classroom, tend to form more positive attitudes overall toward students with intellectual disabilities, (Georgiadi et al., 2012) and physical disability (Kalyva \& Agaliotis, 2009). Additionally, the attendance of a special needs student in classroom forms a conservative to positive attitude toward the total integration of students with special needs in general education school for those students who have a peer with disabilities in their classroom, opposed to students who had not any peer with special needs in their classroom, who seem to express positive attitudes toward the inclusion policy.

Other studies (Kalyva \& Agaliotis, 2009; Panagiotou et al., 2008; Frostad \& Pijl, 2007) showed that typically developing students were willing to accept their peers with disabilities in physical education classes, but they weren't willing for them to be integrated as a member in their team, a case that is attributed to the desire of students to belong to a powerful structured team in order to have the possibilities to win the game. Children who are expressing a sociable attitude to their peers with disabilities may not develop interactions with students with disabilities if that case demands extra effort (Roberts \& Smith, 1999). The experience of a special needs child in classroom, contribute to conditions that allow the expression of a positive attitude toward the students with disabilities, in a way that general classroom students accept the difficulties that are faced by a special need student concerning the school subjects (Gash \& Coffey, 1995) without ensuring the social acceptance and inclusion of these students in the classroom (Gash et al., 2000). Thereby it is indicated the student's willingness to cooperate during the activities or play inside the classroom or during the break time (Laws, \& Kelly, 2005). This observation comes to contradiction with the intention and certainty that is expressed by the typical developing students that special needs students should attend integration classrooms or special needs schools (Soulis et al., 2016), because it is probable that they have an amount of restricted occasions to interact (Tavares, 2011). At the same time, it is noticed that, the participation of both typically developing children and children' $s$ with disability in the same classroom, can increase the cohesion level and decrease the rate of school dropout (Lupu, Cernat, \& Petre, 2011)and develop positive attitudes toward the perspective of inclusive education of children with disabilities (Kalyva \& Agaliotis, 2009). Also, typically developing students are willing to offer help and support to their peers with disabilities, when co-existing in the same classroom, but they notice some different characteristics (Bunch \& Valeo, 2004) and behavior problems can be observed (Daniel \& king, 1997). Inclusion practices in one classroom don't mark naturally the positive attitudes to be expressed from typically developing students to their disabled peers (Pijl, Frostad, \& Flem, 2008; Schwab, Huber, \& Gebhardt, 2016) a fact that depends on social interaction (Diamond, Furgy, \& Blass, 1993). Nevertheless, it is quite clear that a social environment constructed by typically developed peers is proved to be more supported for the social skills development of peers with disabilities in comparison to an environment that is primarily constructed by special needs persons (Guralnick, 1990). Additionally, age is found to be an affecting variable that differentiate children's attitudes who belong to age group 7 to 9 years old and to age group 11 to 13 years old, a finding which was found in a similar study (Royal and Roberts, 1987). The result is a proof of the developmental change regarding the attitude formation (Gash et al., 2000). The grade of positive acceptance of a person with disabilities increases with age(Diamond, Furgy, \& Blass, 1993)and it is obvious that age can affect in a great extent student's comportment toward their special needs peers, (Soulis et al., 2016). Another study revealed that younger children express higher level of acceptance of their peers with disabilities in comparison to older children (Morgan et al., 1998),younger students can express feelings of sympathy that result in the adoption of a positive social attitude (Gash \& Coffey, 1995), or in the same order, they may use positive descriptions while they are getting older (Gash, 1993).A similar study (Nabors \& Larson, 2002), showed that students of 7 to 8 years old hold more positive attitudes and older students expressed less positive attitudes concerning their availability to share their activities with peers in autistic behavior (Swaim and Morgan, 2001).Tavares' research (2011)concluded that children aged from 12 to 13 years old experienced no comfortable feelings to develop a conversation about disability in the presence of their special needs peers. From the other hand, other research (Nowicki, 2006) resulted to the finding that younger students express more negative attitudes toward their peers in mentally retardation behavior, The findings of another study (Tang et al., 2000) revealed that students in the age of primary education expressed their willingness to share social activities and develop friendships with their special educational needs classmates. Additionally, it is observed that grade in primary school affect differently children's social behavior toward children with disability. Especially, students who attend the lower grades in school seem to express more favorable attitudes toward special needs students, a higher level of social interest and they are more willing to interact with these students in a social context. 
This is a finding that comes to accordance with the study of Royal \& Roberts (1987), where primary education students who attend low grades expressed a significant higher level of social acceptance toward children with disabilities in correlation to higher grades students.

\section{Conclusions}

The sample corresponds to a wide range of pupil population, which enables us to express, a high degree of certainty for the generalization of results to students with similar characteristics, using self-reported questionnaires (Sallis\&Saelens, 2000). Children's attitudes are presented to be differentiated in relation to demographic features.

\section{Limitations of the study}

The psychometric tool, which was used for the current study, didn't obtain measurements of attitudes toward different types of disabilities (Avramidis, Bayliss \& Burden, 2000) and there was no behavior observation obtained, as well as the sample representation wasn't taken equally from urban areas and big cities. Demographics characteristics, concerning the education and socio-economic level of the family weren't assessed.

\section{Recommendations for future research}

Ccooperative and equal learning models must be created (Maras \& Brown, 2000), involving the full attendance of special needs students in the general primary school (Tavares, 2011).

\section{References}

Avramidis, E., Bayliss, P., \& Burden, R. (2000). Student teachers' attitudes toward the inclusion of children with special educational needs in the ordinary school. Teaching and teacher education, 16(3), 277-293.

Barch, D. E., Karnes, C., \& Rice, P. (2018). Enhancing children's school success through parent involvement / family engagement programs. Journal of Education and Social Policy, 5(1), 28-34.

Daruwalla, P., \& Darcy, S. (2005). Personal and societal attitudes to disability. Annals of Tourism Research, 32(3), 549-570.

Demellweek, C., Humphris, G. M., Hare, M., \& Brown, J. (1997). Children's Perception of, and Atitude Towards, Unfamiliar Peers with Facial Port-Wine Stains. Journal of pediatric Psychology, 22(4), 471-485.

Diamond, K., Furgy, L. W., \& Blass, S. (1993). Attitudes of Preschool Children Toward Their Peers With Disabilities: A Year-Long Investigation in Integrated Classrooms. The Journal of Genetic Psychology, 154(2), 215.

Eleftheriou, P., Stamou, A. G., Alevriadou, A., \&Tsakiridou, E. (2013). Acomparative study of representations about disability in primary school children's drawings: a sociosemiotic approach. Social Semiotics, 23(5), 663-674.

Frostad, P., \&Pijl, S. J. (2007). Does being friendly help in making friends? The relation between the social position and social skills of pupils with special needs in mainstream education. European Journal of Special Needs Education, 22(1), 15-30.

Gannon, S., \& McGilloway, S. (2009). Children's attitudes towards their peers with Down Syndrome in schools in rural Ireland: an exploratory study. European Journal of Special Needs Education, 24 (4), 455-463.

Gash, H. (1993). A constructivist attempt to change attitudes toward children with special needs. European Journal of Special Needs Education, 8 (2), 106-125.

Gash, H. (1996). Changing attitudes toward children with special needs. European Journal of Special Needs Education, 11 (3), 286-297.

Gash, H., \& Coffey, D. (1995). Influences on attitudes towards children with mental handicap. European Journal of Special Needs Education, 10 (1), 1-16.

Gash, H., \& Feerick, A. (1996). Promoting quality through changing attitudes towards children with mental handicap. Irish Educational Studies, 15(1), 237-251.

Gash, H., Gonzalez, S. G., Pires, M., \& Rault, C. (2000). Attitudes toward Down Syndrome: A national comparative study in France, Ireland, Portugal and Spain. The Irish Journal of Psychology, 21 (3-4), 203-214.

Georgiadi, M., Kalyva, E., Kourkoutas, E., \& Tsakiris, V. (2012). Young children's attitudes toward peers with intellectual disabilities: Effect of the type of school. JournalofAppliedResearchinIntellectualDisabilities, 25, 531-541.

Guralnick, M. J. (1990). Social competence and early intervention. Journal of early intervention, 14(1), 3-14.

Kazimi, A. B., \& Kazmi, S. W. (2018). Developing inclusive education approaches among stakeholders in Pakistan. Journal of Education and Social Sciences, 6(1), 86-95. DOI: 10.20547/jess0611806106 
Kalyva, E., \& Agaliotis, I. (2009). Can contact affect Greek children's understanding of and attitudes towards peers with physical disabilities? European Journal of Special Needs Education, 24 (2), 213-220.

Katsama, I., \& Bourmpaki, E. (2017). Bullying prevention in primary education: a social work intervention with students. Journal of Education and Social Policy, 4(3), 98-111.

Learning and National Certification Agency Qualifications and Vocational Guidance and other provisions". (In Greek)

Laws, G., \& Kelly, E. (2005). The attitudes and friendship intentions of children in United Kingdom mainstream schools towards peers with physical or intellectual disabilities. International Journal of Disability, Development and Education, 52(2), 79-99.

Lupu, E., Cernat, C., \& Petre, C. (2011). Identifying the attitude of healthy individuals towards disabled children-A chance to be educated for all. Procedia-Social and Behavioral Sciences, 29, 266-271.

Magiati, I., Dockrell, J. E., \& Logotheti, A. E. (2002). Young children's understanding of disabilities: the influence of development, context and cognition. Applied Developmental Psychology, 23, 409-430.

Martinez, R. S., \& Carspecken, P. (2007). Effectiveness of a brief intervention on Latino children's social acceptance of peers with special needs. Journal of Applied School Psychology, 23(1), 97-115.

Morgan, S. B., Bieberich, A. A., Walker, M., \& Schwerdtfeger, H. (1998). Children's willingness to share activities with a physically handicapped peer: Am I more willing than my classmates? Journal of Pediatric Psychology, 23(6), 367-375.

Morgan, S. B., \& Wisely, D. W. (1996). Children's attitudes and behavioral intentions toward a peer presented as physically handicapped: A more positive view. Journal of Developmental and Physical Disabilities, 8(1), 2942.

Nowicki, E. A. (2006). A cross- sectional multivariate analysis of children's attitudes towards disabilities. Journal of Intellectual Disability Research, 50(5), 335-348.

Oswalt, M., \&Swart, E. (2011). Addressing South-African preservice teachers' sentiments, attitudes, and concerns regarding inclusive education. International Journal of Disability, Development and education, 58 (4), 389403.

Panagiotou, A. K., Evaggelinou, C., Doulkeridou, A., Mouratidou, K., \&Koidou, E. (2008). Attitudes of 5th and 6th grade Greek students toward the inclusion of children with disabilities in physical education classes after a Paralympic education program. European Journal of Adapted Physical Activity, 1(2), 31-43.

Pijl, S. J., Frostad, P., \&Flem, A. (2008). The social position of pupils with special needs in regular schools. Scandinavian Journal of Educational Research, 52(4), 387-405.

Roberts, C. M., \& Smith, P. R. (1999). Attitudes and behaviour of children toward peers with disabilities. International Journal of Disability, Development and Education, 46(1), 35-50.

Sallis, J. F., \& Saelens, B. E. (2000). Assessment of physical activity by self-report: status, limitations, and future directions. Research quarterly for exercise and sport, 71(sup2), 1-14.

Shamsi, F., Adibsereshki, N., Movallali, G., \&Mahvashe, V. A., (2014). The effect of an awareness program on attitude change of female students towards the sociability and educational situation of their peers with physical disorder in inclusive primary schools. Journal of Research in Rehabilitation Sciences, 10 (1), 113-122.

Sharma, U., Loreman, T., \&Forlin, C. (2012). Measuring teacher efficacy to implement inclusive practices. Journal of Research in Special Educational Needs, 12(1), 12-21.

Siperstein, G. N., Parker, R. C., Norins, J., \&Widaman, K. F. (2011). A national study of Chinese youths' attitudes towards students with intellectual disabilities. Journal of Intellectual Disability Research, 55(4), 370-384.

Skär, L. (2010). Children's conceptions of the word 'disabled': a phenomenographic study. Disability \& Society, 25(2), 177-189.

Soulis, S. G., Georgiou, A., Dimoula, K., \&Rapti, D. (2016). Surveying inclusion in Greece: empirical research in 2683 primary school students. International Journal of Inclusive Education, 1-14.

Swaim, K. F., \& Morgan, S. B. (2001). Children's attitudes and behavioral intentions toward a peer with autistic behaviors: Does a brief educational intervention have an effect?. Journal of autism and developmental disorders, 31(2), 195-205.

Tang C. S. K., Davis, C., Wu, A., \& Oliver, C. (2000). Chinese children's attitudes toward Mental Retardation. Journal of Developmental and Physical Disabilities, 12 (1).

Tavares, W. (2011). An evaluation of the Kids are Kids disability awareness program: Increasing social inclusion among children with physical disabilities. Journal of social work in disability \& rehabilitation, 10(1), 25-35.

Vignes, C., Godeau, E., Sentenac, M., Coley, N., Navarro, F., Grandjean, H., \& Arnaud, C. (2009). Determinants of students' attitudes towards peers with disabilities. Developmental Medicine \& Child Neurology, 51(6), 473479. 